\title{
Low-dose Exposure to Black Carbon and Cadmium Significantly Induce Lung Injury by Promoting Cellular Apoptosis
}

\section{Lingjuan Wang}

Tianjin Medical University General Hospital

\section{Shanyu Bao}

Tianjin Medical University General Hospital

Xiaolong Liu

Tianjin Medical University General Hospital

\section{Fan Wang}

Tianjin Medical University General Hospital

Jinwei Zhang

Tianjin Medical University General Hospital

\section{Peng yu Dang}

Tianjin Medical University General Hospital

\section{Wen Huang}

Tianjin Medical University General Hospital

\section{Bin Li ( $\nabla$ sdwhlb@163.com )}

Tianjin Medical University General Hospital https://orcid.org/0000-0002-3769-7476

Yi Lin

Tianjin Medical University General Hospital

\section{Research Article}

Keywords: PM2.5, Carbon black, Cd, BEAS-2B cells, Apoptosis

Posted Date: April 12th, 2021

DOl: https://doi.org/10.21203/rs.3.rs-344122/v1

License: (c) (i) This work is licensed under a Creative Commons Attribution 4.0 International License. Read Full License 


\section{Abstract}

PMs has adverse biological effects on major living organs in the body, including lungs. The complex composition of $\mathrm{PM}_{2.5}$, including carbon black and heavy metals, cause toxic effects to the lung. The synergistic effects of $\mathrm{CB}$ and $\mathrm{Cd}$ were less investigated in previous study. In our research, we deciphered the combination of $\mathrm{CBs}$ and $\mathrm{Cd}$ enhanced the cytotoxicity in BEAS-2B cells in vitro and in vivo. In the molecular level, the intracellular level of $\mathrm{Cd}$ increased, as a result of the cell membrane damage, causing high expression of MT-1 in BEAS-2B cells. Moreover, the expression of BAX increased, and the expression of BCL-2 decreased. Collectively, our data suggests the apoptosis effect of synergistic effects of CB and Cd exposure.

\section{Introduction}

In recent years, particulate matter (PM) is a hot topic in public health research. Epidemiological studies have revealed a negative correlation between PM inhalation and life expectancy (Aboubacar et al. 2018; Dziubanek et al. 2017). In addition, PM has adverse biological effects on several major living organs in the body, such as lungs. Fine particulate matter (PM2.5; aerodynamic diameter, $<2.5 \mu \mathrm{m}$ ) is a well-known air pollutant that threatens public health. Exposure to high levels of PM2.5 in the air has been linked to the risk of atherosclerosis (Woo et al. 2020), respiratory diseases (Pun et al. 2017) and lung cancer (Yang et al. 2020). The toxicity of PM2.5 is mainly due to its small size, which allows it to escape the body's inherent defense mechanism, enter the bronchi and eventually reach the alveoli. Moreover, its complex composition, often adsorption of toxic substances, including endotoxins, polycyclic aromatic hydrocarbons, sulfate and heavy metals, will also cause toxic effects, among which cadmium, black carbon is found to be more toxic, the most serious impact on health components. Since environmental problems cannot be fully addressed immediately, it is important to identify targeted prevention and treatment strategies to protect the human respiratory system from PM-induced lung injury.

Air, soil and even water contain heavy metals, such as free radicals that cause aging, fine particles that harm the skin, dust in the air, automobile exhaust, etc. Even tap water brings heavy metals to the skin, and some heavy metal raw materials such as cadmium in skin care products such as moisturizers are also one of them. The accumulation of heavy metals can be quite harmful to human health. Cadmium inhalation was reported to induce pulmonary damage, such as emphysema, fibrosis, et al (Niewoehner and Hoidal 1982; Snider et al. 1988).

Black carbon is composed of elemental carbon, which is generated hydrocarbon through incomplete combustion and vapor phase pyrolysis (Gardiner et al. 1992). It is black, fluffy and powdery. Black carbon particles, which have a large surface area and can aggregate in sizes ranging from 10 nanometers to a few hundred nanometers, are one of the components of PM2.5. Particles of this size can easily enter the respiratory tract and induce respiratory symptoms (Falcon-Rodriguez et al. 2016), including cough, sputum production, wheezing and dyspnea and with changes in pulmonary function, especially forced 
vital capacity (FVC) and forced expiratory volume in 1 second (FEV1) (Wong et al. 2016; Zhao et al. 2015).

Previous work has shown that $\mathrm{CB}$ exposure can trigger systemic inflammation and lead to a range of respiratory diseases including lung injury (Jia et al. 2020; Yang et al. 2018). However, the effects of CB combined with cadmium exposure on alveolar epithelial cells have not been reported. Therefore, in this study, we explored whether the combined exposure of $\mathrm{CB}$ and cadmium can significantly enhance the toxicity of lung cells and the related mechanism of action, providing theoretical basis for the prevention or treatment of air pollution diseases in the future. From the perspective of lung cell injury, this study puts forward a higher concern on environmental health and safety (EHS) of atmospheric particulates.

\section{Materials And Methods}

\subsection{Preparation and characterization of black carbon and cadmium}

The carbon black powders (Printex U and SB4A) are purchased from Degussa Inc. Corp. The carbon black was adjusted to $2 \mathrm{mg} / \mathrm{mL}$ and ultrasonically with $100 \mathrm{~Hz}, 200 \mathrm{~W}$ water bath for $2 \mathrm{~h}$. The morphology of the CB samples was tested with The transmission electron microscope (TEM). To test the hydrated particle size of the CB samples, Zeta-sizer was carried out. Afterwards, X-ray photoelectron spectroscopy (XPS) was tested to identify the surface functional groups.

\subsection{Cell line and cell culture}

The human lung epithelial cell line (BEAS-2B) was purchased from the American Type Culture Collection (Manassas, VA, USA) and cells were cultured in phenol red-free RPMI-1640 medium (Gibco BRL Life Technologies Inc, USA), supplemented with $10 \%$ fetal bovine serum (FBS) and $1 \%$ penicillin/streptomycin (Invitrogen) in the humidified incubator with $5 \% \mathrm{CO} 2$ at $37^{\circ} \mathrm{C}$, as reported (Li et al. 2019).

\subsection{Cytotoxicity assay}

Cytotoxicity of CBs (SB4A/ Printex U) was tested according to the manufacturer's protocol of Cell Counting Kit-8 (CCK-8) (Solarbio Science \& Technolo Co., Ltd., Beijing, China). 2,000 BEAS-2B cells were inoculated into 96-well plates, and lung epithelial cells were subjected to different concentration of CBs $\nabla 10,20,20,100,200 \mu \mathrm{g} / \mathrm{ml}$ and Cadmiun $(0.1,0.5,1,2,5 \mu \mathrm{M})$ at different concentration for $24 \mathrm{~h}$. The cell viability of cells was determined following the provided reagents as previous reported (Zhu et al. 2020).

\subsection{Confocal assay}

BEAS-2B cells were seeded into 6-well plates, exposed with CBs at concentration of $20 \mu \mathrm{g} / \mathrm{ml}$, following with/without Cd treatment for $24 \mathrm{~h}$. BEAS-2B cells were then incubated with PI staining for $20 \mathrm{~min}$ at room temperature. PI fluorescence of PI was tested with TCS SP5 microscope (excited at $488 \mathrm{~nm}$ and visualized at $630 \mathrm{~nm})$. The photographs of lung cells were taken at random fields with $(n=4)$. 


\subsection{Flow cytometric apoptotic cell death analysis by annexin V FITC- PI staining}

BEAS-2B cells $\left(1 \times 10^{5}\right)$ were stained with anti-annexin $\mathrm{V}$ and propidium iodide $(\mathrm{PI})$ antibody, according to the manufacturer's protocol (KeyGen Biotech, Nanjing, People's Republic of China). Afterwards, apoptosis ability of BEAS-2B cells were analyzed in the fluorescence-activated cell sorting (BD, Franklin Lakes, USA). Percentage of death cells were corresponded to annexin $\mathrm{V}^{+}-\mathrm{PI}^{+}$, and the percentage of apoptotic death cells was shown with annexin $\mathrm{V}^{+}-\mathrm{PI}^{-}$.

\subsection{Western blot analysis}

Various proteins in cells protein concentrations were performed with Western blot analysis as previously described (Wang et al. 2019). Cells were harvested, and then lysed in RIPA lysis buffer for $30 \mathrm{~min}$. After measured with BCA protein assay kit, equal amounts of protein were subjected to SDS-PAGE electrophoresis, followed by Western blotting. Afterwards, proteins were transferred to PVDF membranes (Millipore). The primary antibodies (Abs) and the secondary antibodies were shown in Fig. S1. $\beta$-actin was used as a loading control for normalization with software Image $\mathrm{J}$.

\subsection{RNA expression analysis by real-time quantitative PCR (RT-qPCR)}

BEAS-2B cells were treated with $\mathrm{CBs}(0,20,50 \mu \mathrm{g} / \mathrm{ml})$ at different concentrations for $24 \mathrm{~h}$. Expression of RNA was tested with Real-time PCR as previously described (Gao et al. 2020). $\beta$-actin was used as the invariant control. Results were from experiments in triplicate. All of the primer sequences for PCR analysis are presented in Table S1.

\subsection{Animal experiment}

BALB/C male mice (6-8 weeks old) were purchased from the Beijing Vital River Laboratory Animal Technology, and housed in aseptic animal facility under specific pathogen-free (SPF grade). BALB/C male mice were divided into 6 groups (5 mice in each group). CBs $(2.5 \mathrm{mg} / \mathrm{kg})$ and $\mathrm{Cd}(10 \mathrm{mg} / \mathrm{L})$ were intratracheally instilled into mice with lung exposure after intraperitoneal anesthesia (pentobarbital sodium). For the combination of CBs and Cd, mice were treated with CBs following with $\mathrm{Cd}$ after $24 \mathrm{~h}$. Mice were sacrificed $24 \mathrm{~h}$ post administration for 4 weeks, and mice were sacrificed $24 \mathrm{~h}$ post the last administration. As positive control, lipopolysaccharide (LPS) was intratracheally instilled into the lungs with $2.5 \mathrm{mg} / \mathrm{kg}$ body weight. All animal experimental protocols were approved by the Animal Ethics Committee at the Research Center for Eco Environmental Sciences, Chinese Academy of Sciences.

\subsection{Histological analysis and immunohistochemistry analysis}

Lung tissues were fixed with $10 \%$ formaldehyde solution in PBS after sacrificed. After embedded in paraffin, the lung tissue specimens were sliced into sections at thicken of $4 \mu \mathrm{m} \Downarrow$ following with hematoxylin-eosin (H\&E) staining with standard protocols. Briefly, slices were pictured with optical microscope (Axio Scope A1, Carl Zeiss, Inc., Germany). The photographs of fields on each slide were taken at random fields with $(n=10)$. 


\subsection{Statistical analysis}

All data were represented in terms of the mean \pm standard deviation (SD). Statistical analysis was performed with independent t-test or One-Way ANOVA test. Values were considered to be statistically significant with *: $P<0.05$ and \#: $P<0.001$.

\section{Results And Discussion}

\section{Characterization of two black carbon materials}

All carbon black nanomaterial were characterized with TEM. The TEM images (Fig. 1A) showed the grape-like morphology nanoparticles of carbon black. The hydrodynamic size in culture media was 195.4 $\mathrm{nm}$ for SB4A, and $196.7 \mathrm{~nm}$ for Printex U. XPS spectra were also teste to determine functional groups in the $\mathrm{CB}$ samples. Together, our CB samples contained similar functional groups, which might cause approximate biological effects.

\section{Screening and ascertaining the combined exposure concentration of cadmium and black carbon}

To study the effects of CBs and Cd on lung epithelial cells, the toxicity of CBs and Cd to BEAS-2B cells by measuring the cell apoptosis by CCK-8 assay. CBs (SB4A and Printex $U$ ) showed no obvious cytotoxicity in the assay at a concentration range from 10 to $100 \mu \mathrm{g} / \mathrm{L}$, as shown in Fig. 2. CBs significantly affected cell proliferation at high concentration $(200 \mu \mathrm{g} / \mathrm{L})$, inhibiting growth more than $20 \%$ (Fig. A and B), thereby suggesting the exposure concentration of CBs was lethal doses, as demonstrated previously (Ren et al. 2019). There was no significant difference apoptosis cell ratio between SB4A and Printex $U$ at the same exposure concentration. Also, Cd reduced the viability of BEAS-2B cells compared to the NC significantly with high concentration $(5 \mu \mathrm{M})$. High concentration of $\mathrm{CB}$ and $\mathrm{Cd}$ were not further investigated, for the high concentrations would cause significantly cell death and was not environmentally relevant. Thus,concentration of $\mathrm{CBs}$ and $\mathrm{Cd}$ in subsequent experiments was selected at level of $100 \mu \mathrm{g} / \mathrm{L}$ and $1 \mu \mathrm{M}$, respectively.

\section{BCs synergizes with $\mathrm{Cd}$ for apoptosis in vitro}

The loss of membrane integrity leads to a compromised cytoskeletal meshwork(Xu et al. 2016), elevating cellular uptake of metal ions, resulting in cell death. To test whether CB pre-treatment caused loss of membrane integrity, the membrane permeability of BEAS-2B cells was assessed upon CB treatment. Lactate dehydrogenase ( $L D H)$ was present in the cytoplasm, thus concentration of LDH in culture medium is a common method for detecting cell membrane damage (cell membrane permeability) (Gissel and Clausen 2001; Kumar et al. 2018). Therefore, concentration of LDH was biomarker for ensuring normal function integrity of cell membrane. CBs caused LDH release of BEAS-2B cells at concentration of $100 \mu \mathrm{g} / \mathrm{L}$ at $24 \mathrm{~h}$ (Fig. S6). Consistent with our suppose, treatment of CBs may cause the collapse of the cell membrane, thus the permeability of BEAS-2B cells increased. 
Disruption of cell membrane structural might lead to the loss of defense against Cd,resulting high level of $\mathrm{Cd}$ in cytoplasm. In our research, high concentration of CBs suppressed the development of BEAS-2B cells, we supposed whether CBs synergizes with $\mathrm{Cd}$ for apoptosis in vitro. In the research of potential mechanism of the sequential exposure of CBs and Cd, we intentionally used sublethal doses of CBs and $\mathrm{Cd}(100 \mathrm{ug} / \mathrm{L}$ and $1 \mathrm{uM})$. To verify our hypothesis, BEAS-2B cells were pre-treated with CBs at $100 \mu \mathrm{g} / \mathrm{L}$ for $24 \mathrm{~h}$, afterwards we replaced culture medium with $\mathrm{Cd}(1 \mu \mathrm{M})$ for $24 \mathrm{~h}$ (Fig. 3A). Cytotoxicity assay was tested with CCK-8, our data reflected CBs synergizes with Cd effectively suppressed the viability of BEAS$2 B$ cells ( $20 \%$ of SB4A and $25 \%$ of Printex $U$ ), compared to that of $\mathrm{Cd}$ alone at low concentration in Fig. 2D. In agreement with our hypothesis, apoptosis of BEAS-2B cells was determined by confocal assay (PI staining) and flow cytometric (Annexin-V FITC and PI staining). CBs and Cd increased cell death only slightly at low concentration. Interestingly, pre-treatment of BCs significantly induced cell death than Cd alone in the experiment of flow cytometric, 1.8 fold of SB4A and 1.7 fold of Printex $U$ respectively (Fig. 4S4 and S5). Similar results were observed with confocal assay (Fig. 5).

\section{Combined exposure of $\mathrm{BCs}$ and $\mathrm{Cd}$ cause lung damage}

$\mathrm{PM}_{2.5}$ is now public health research, mainly caused by traffic-related pollution. Nanoparticle of PM2.5 is a complex mixture of gaseous and particulate, of which black carbon is the key component (Secrest et al. 2016). Previous studies have showed the damage effect of invading particles, including CB and Cd, as characterized by inflammatory cells infiltration (Wu et al. 2020), alveolar thickening and swelling (Ping et al. 2016). To evaluate the in vivo effect of CBs synergizes with $C d$, we used mice exposed of CBs and Cd. As shown in Fig. 6, the histological characterization revealed the structure of lung tissue. The dispersed particles in lung tissues could be seen in mice, the BCs and Cd treated group showed no significant lung inflammation when compared with control group. There were no obvious inflammatory cells infiltration, alveolar thickening and swelling. Interestingly, the combined exposure of BCs and Cd caused much more significant inflammation of lung than BCs and $\mathrm{Cd}$ alone, verifying our suppose. The results of related animal experiments showed that the lung tissues were significantly damaged after the combined exposure of black carbon and cadmium.

\section{Synergy of CBs and Cd attributable to production of intracellular ROS}

To explore the mechanism of our results, our data demonstrate that $\mathrm{CB}$ can significantly induce the lowdose non-toxic concentrations of $\mathrm{Cd}$, pretreatment of $\mathrm{CB}$ significantly elevate intracellular nonessential metal ions, causing cell death with increased ROS. To confirm the hypothesis of our hypothesis, we exam the relatively molecular targets of BAX and BCL-2(Hassan et al. 2014; Zhang et al. 2006), serving as clinical apoptosis biomarkers. As shown in Fig. 7, protein expression levels of BCL2 were significantly down-regulated in BEAS-2B cells treated with combined exposure of BCs and $\mathrm{Cd}$. Moreover, intracellular level of BAX was up-regulated when BEAS-2B cells were pretreated with $\mathrm{CBs}$ and $\mathrm{Cd}$. These results also reflected the intracellular level of Cd play an important role for apoptosis of lung epithelial cells. It is plausible to consider that $\mathrm{CB}$ synergy with $\mathrm{Cd}$ could significantly promote lung cell damage. The enhanced accumulation of intracellular metal ion due to CB pre-treatment, which lead to increased 
cytotoxicity and apoptosis subjected to high intracellular Cd, shown in Fig. 7B. Taken together, our data underscore strong theoretical basis for the environmental pollutant, $\mathrm{CB}$, enhancing cell damage to lung cells. Overall, our data propose a new perspective to explore the mechanism of airborne particles synergy with Cd.

\section{Conclusions}

To summarize, present study uncovers the cytotoxicity of CB towards lung cells, inducing cell apoptosis at high concentration. In our research, our data demonstrate that $C B$ can significantly induce the even at low-dose non-toxic concentrations, CB can significantly elevate intracellular nonessential metal ions, inducing cell death with increased oxidative stress. Besides, targeting molecular targets, including MT1, BAX and BCL-2, may also serve as clinical apoptosis biomarkers of lung cells. It is plausible to consider that $\mathrm{CB}$ synergy with $\mathrm{Cd}$ could significantly promote cell damage of patients. Taken together, our data underscore strong theoretical basis for the environmental pollutant, $\mathrm{CB}$, enhancing cell damage to lung cells. Overall, our data propose a new perspective to evacuate the risks of airborne particles synergy with Cd.

\section{Declarations}

\section{Availability of data and materials}

Datasets used and/or analyzed during the current study are available from the corresponding author on reasonable request.

\section{Author contribution}

Lingjuan Wang, Shanyu Bao and Xiaolong Liu carried out the experiments and drafted the introduction of the manuscript.

Bin Li and Yi Lin: supervised the project and contributed to the final manuscript.

Fan Wang: helped supervise the project.

Wen Huang: interpret the results and work on the manuscript.

Pengyu Dang and Jinwei Zhang: help interpreting the results and writing the manuscript.

\section{Funding}

This research was supported by Tianjin Health Commission (Grant No. RC20138).

\section{Ethics approval and consent to participate}

Not applicable 


\section{Consent for publication}

Not applicable

\section{Competing interests}

The authors declare no competing interests

\section{References}

1. Aboubacar, B., Deyi, X., Razak, M. Y. A., and Leyla, B. H. (2018). "The Effect of PM2.5 from. Household Combustion on Life Expectancy in Sub-Saharan Africa." Int J Environ Res Public Health, 15(4).

2. Dziubanek, G., Spychala, A., Marchwinska-Wyrwal, E., Rusin, M., Hajok, I., Cwielag-Drabek, M., and Piekut, A. (2017). "Long-term exposure to urban air pollution and the relationship with life expectancy in cohort of 3.5 million people in Silesia." Sci Total Environ, 580, 1-8.

3. Falcon-Rodriguez, C. I., Osornio-Vargas, A. R., Sada-Ovalle, I., and Segura-Medina, P. (2016). "Aeroparticles, Composition, and Lung Diseases." Front Immunol, 7, 3.

4. Gao, M., Dong, Z., Sun, J., Liu, W., Xu, M., Li, C., Zhu, P., Yang, X., Shang, X., Wu, Y., and Liu, S. (2020). "Liver-derived exosome-laden IncRNA MT1DP aggravates cadmium-induced nephrotoxicity." Environ Pollut, 258, 113717.

5. Gardiner, K., Trethowan, W. N., Harrington, J. M., Calvert, I. A., and Glass, D. C. (1992). "Occupational exposure to carbon black in its manufacture." Ann Occup Hyg, 36(5), 477-96.

6. Gissel, H., and Clausen, T. (2001). "Excitation-induced Ca2+ influx and skeletal muscle cell damage." Acta Physiol Scand, 171(3), 327-34.

7. Hassan, M., Watari, H., AbuAlmaaty, A., Ohba, Y., and Sakuragi, N. (2014). "Apoptosis and molecular targeting therapy in cancer." Biomed Res Int, 2014, 150845.

8. Jia, H., Liu, Y., Guo, D., He, W., Zhao, L., and Xia, S. (2020). "PM2.5-induced pulmonary inflammation via activating of the NLRP3/caspase-1 signaling pathway." Environ Toxicol.

9. Kumar, P., Nagarajan, A., and Uchil, P. D. (2018). "Analysis of Cell Viability by the Lactate Dehydrogenase Assay." Cold Spring Harb Protoc, 2018(6).

10. Li, B., Esposito, B. P., Wang, S., Zhang, J., Xu, M., Zhang, S., Zhang, Z., and Liu, S. (2019). "Desferrioxamine-caffeine shows improved efficacy in chelating iron and depleting cancer stem cells." J Trace Elem Med Biol, 52, 232-238.

11. Niewoehner, D. E., and Hoidal, J. R. (1982). "Lung fibrosis and emphysema: divergent responses to a common injury?" Science, 217(4557), 359-60.

12. Ping, F., Li, Z., Zhang, F., Li, D., and Han, S. (2016). "Effects of Lianhua Qingwen on Pulmonary Oxidative Lesions Induced by Fine Particulates (PM2.5) in Rats." Chin Med Sci J, 31(4), 233-8.

13. Pun, V. C., Kazemiparkouhi, F., Manjourides, J., and Suh, H. H. (2017). "Long-Term PM2.5 Exposure and Respiratory, Cancer, and Cardiovascular Mortality in Older US Adults." Am J Epidemiol, 186(8), 
961-969.

14. Ren, Q., Wu, Y., Ma, J., Shan, Q., Liu, S., and Liu, Y. (2019). "Carbon black-induced detrimental effect on osteoblasts at low concentrations: Remarkably compromised differentiation without significant cytotoxicity." Ecotoxicol Environ Saf, 178, 211-220.

15. Secrest, M. H., Schauer, J. J., Carter, E. M., Lai, A. M., Wang, Y., Shan, M., Yang, X., Zhang, Y., and Baumgartner, J. (2016). "The oxidative potential of PM2.5 exposures from indoor and outdoor sources in rural China." Sci Total Environ, 571, 1477-89.

16. Snider, G. L., Lucey, E. C., Faris, B., Jung-Legg, Y., Stone, P. J., and Franzblau, C. (1988). "Cadmiumchloride-induced air-space enlargement with interstitial pulmonary fibrosis is not associated with destruction of lung elastin. Implications for the pathogenesis of human emphysema." Am Rev Respir Dis, 137(4), 918-23.

17. Wang, L., Zhuang, T., Li, F., and Wei, W. (2019). "Fluorene-9-bisphenol inhibits epithelial-mesenchymal transition of human endometrial cancer Ishikawa cells by repressing TGF-beta signaling pathway." Environ Sci Pollut Res Int, 26(26), 27407-27413.

18. Wong, S. L., Coates, A. L., and To, T. (2016). "Exposure to industrial air pollutant emissions and lung function in children: Canadian Health Measures Survey, 2007 to 2011." Health Rep, 27(2), 3-9.

19. Woo, K. S., Chook, P., Hu, Y. J., Lao, X. Q., Lin, C. Q., Lee, P. W. A., Kwok, C. Y. T., Wei, A. N., Guo, D. S., Yin, Y. H., Lau, K. H. A., Leung, K. S., Leung, Y., and Celermajer, D. S. (2020). "The impact of particulate matter air pollution (PM2.5) on atherosclerosis in modernizing China: a report from the CATHAY study." Int J Epidemiol.

20. Wu, M. Y., Ying, Y. Y., Zhang, S. S., Li, X. G., Yan, W. H., Yao, Y. C., Shah, S., Wu, G., and Yang, F. L. (2020). "Effects of Diallyl Trisulfide, an Active Substance from Garlic Essential Oil, on Energy Metabolism in Male Moth Sitotroga cerealella (Olivier)." Insects, 11(5).

21. Xu, M., Zhu, J., Wang, F., Xiong, Y., Wu, Y., Wang, Q., Weng, J., Zhang, Z., Chen, W., and Liu, S. (2016). "Improved In Vitro and In Vivo Biocompatibility of Graphene Oxide through Surface Modification: Poly(Acrylic Acid)-Functionalization is Superior to PEGylation." ACS Nano, 10(3), 3267-81.

22. Yang, B., Guo, J., and Xiao, C. (2018). "Effect of PM2.5 environmental pollution on rat lung." Environ Sci Pollut Res Int, 25(36), 36136-36146.

23. Yang, D., Liu, Y., Bai, C., Wang, X., and Powell, C. A. (2020). "Epidemiology of lung cancer and lung cancer screening programs in China and the United States." Cancer Lett, 468, 82-87.

24. Zhang, T. J., Hang, J., Wen, D. X., Hang, Y. N., and Sieber, F. E. (2006). "Hippocampus bcl-2 and bax expression and neuronal apoptosis after moderate hypothermic cardiopulmonary bypass in rats." Anesth Analg, 102(4), 1018-25.

25. Zhao, J., Bo, L., Gong, C., Cheng, P., Kan, H., Xie, Y., and Song, W. (2015). "Preliminary study to explore gene-PM2.5 interactive effects on respiratory system in traffic policemen." Int J Occup Med Environ Health, 28(6), 971-83.

26. Zhu, J., Li, B., Xu, M., Liu, R., Xia, T., Zhang, Z., Xu, Y., and Liu, S. (2020). "Graphene Oxide Promotes Cancer Metastasis through Associating with Plasma Membrane To Promote TGF-beta Signaling- 
Dependent Epithelial-Mesenchymal Transition." ACS Nano, 14(1), 818-827.

\section{Figures}

Fig. 1

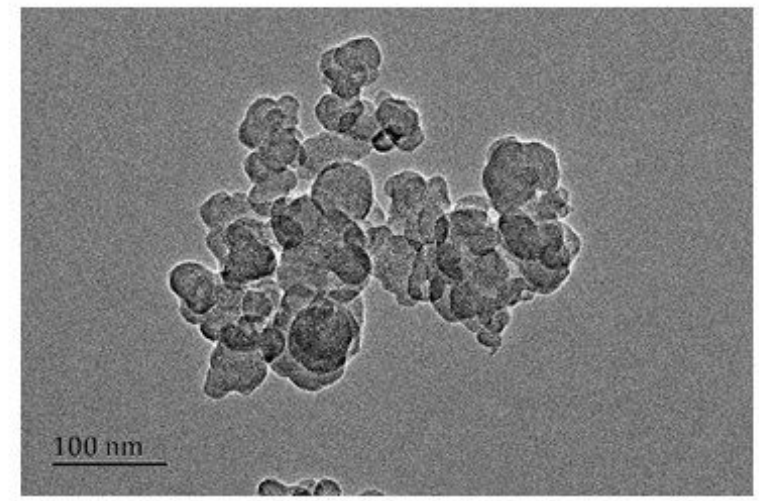

SB4A

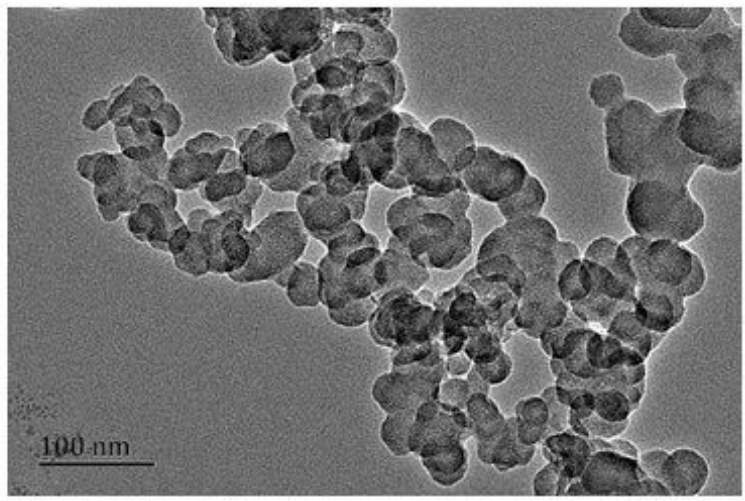

Printex U

\section{Figure 1}

physicochemical characterization of CB nanomaterial. SEM image of CB nanomaterial SB4A and Printex $\mathrm{U}$. The scale bar is $100 \mathrm{~nm}$. 
Fig. 2

(A)

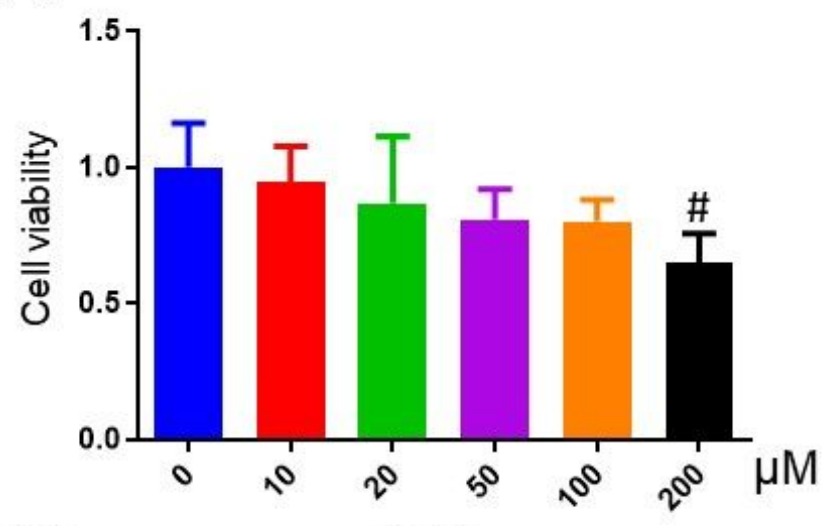

(C)

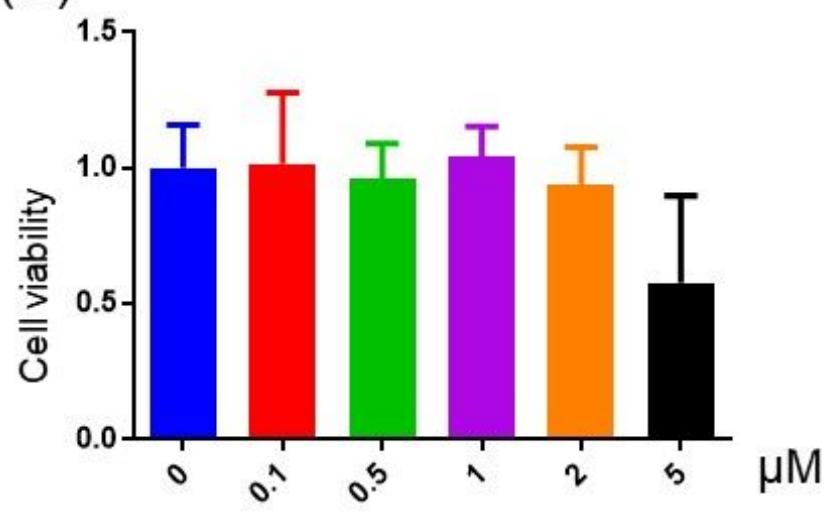

(B)

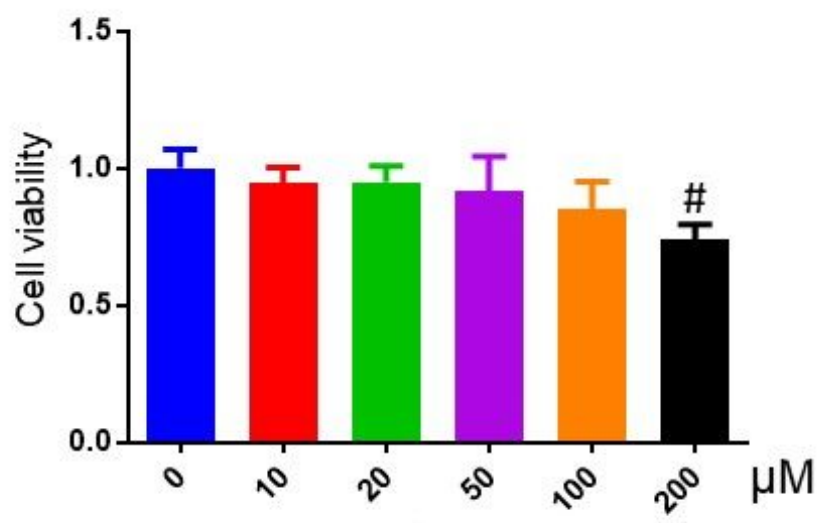

(D)

Printex U

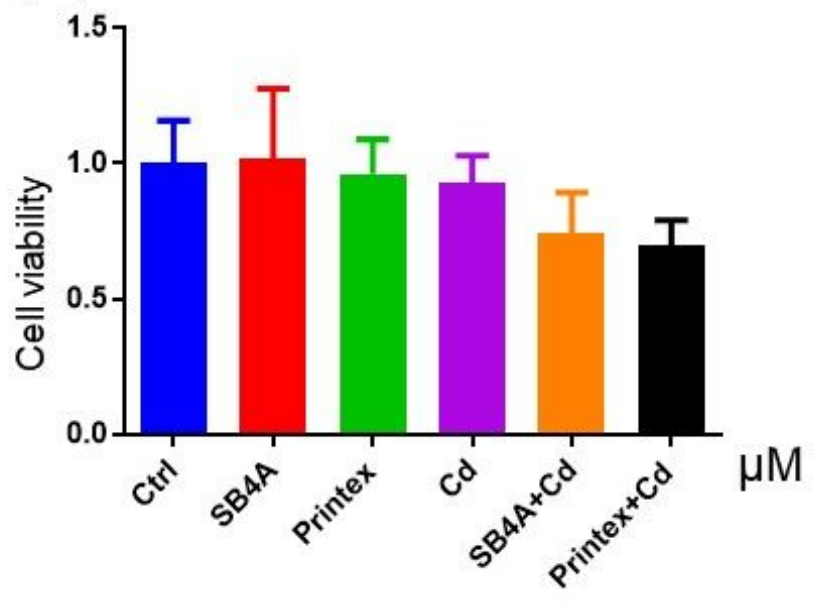

Figure 2

BEAS-2B cells were treated with CB nanomaterial and Cd at different for $24 \mathrm{~h}(0,10,50,100,200 \mu \mathrm{g} / \mathrm{L}$ for $\mathrm{CB}$ nanomaterial) CCK8 assay was measured for cell viability (2A, $B$ and $C$ ). Cell viability of BEAS-2B cells after treatment of $\mathrm{CBs}$ and $\mathrm{Cd}$ or combination of both (2D). The experiment was repeated five times, and data are reported as the means $\pm S D$. 
Fig. 3

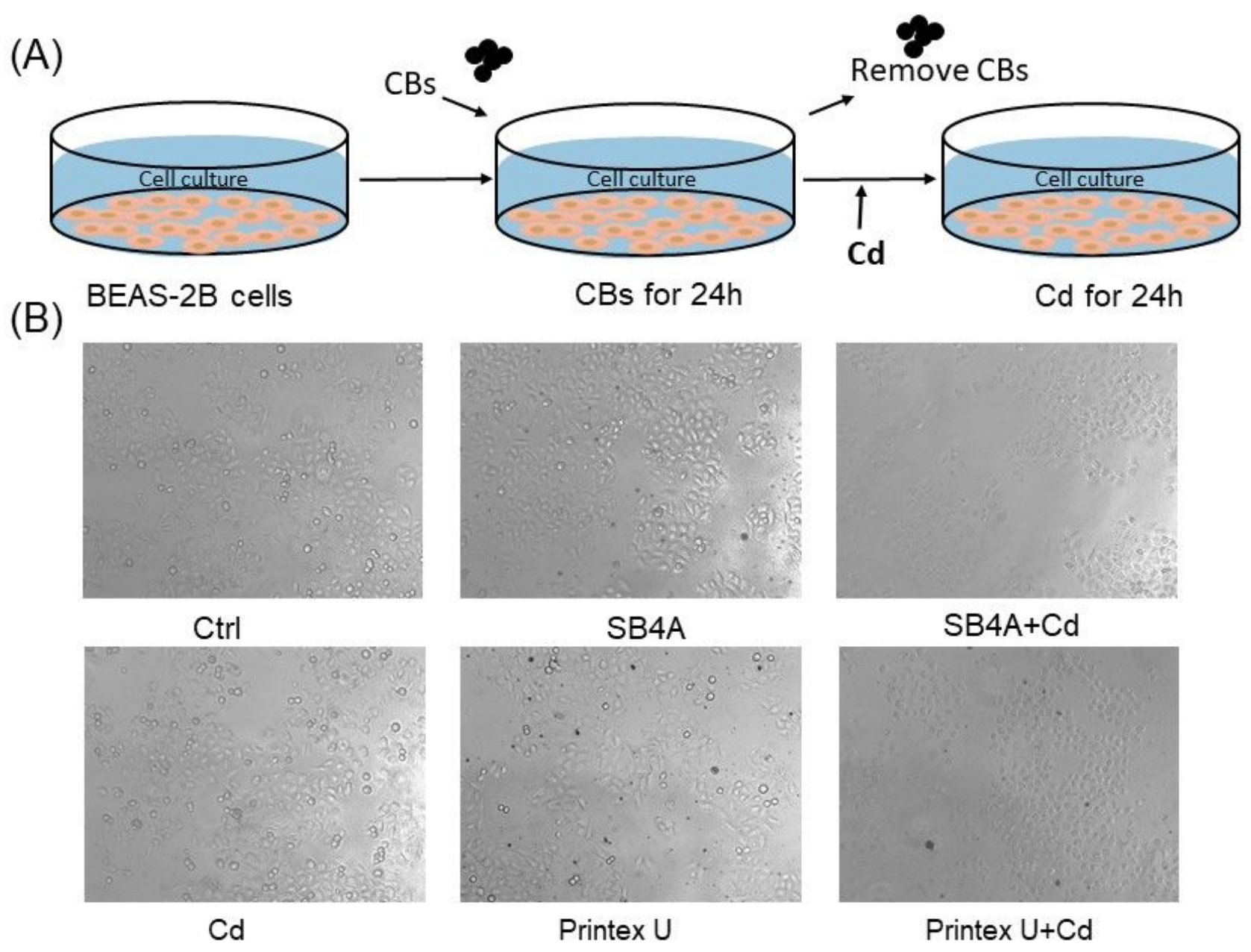

\section{Figure 3}

Cellular status of BEAS-2B cells after treatment of CB materials. (3A) The experimental processes of combination exposure of both $\mathrm{CB}$ materials. (3B) Morphological changes of the cells after exposure to $\mathrm{CBs}$ and $\mathrm{Cd}$ or combination of both $\mathrm{CB}$ materials. 
Fig. 4

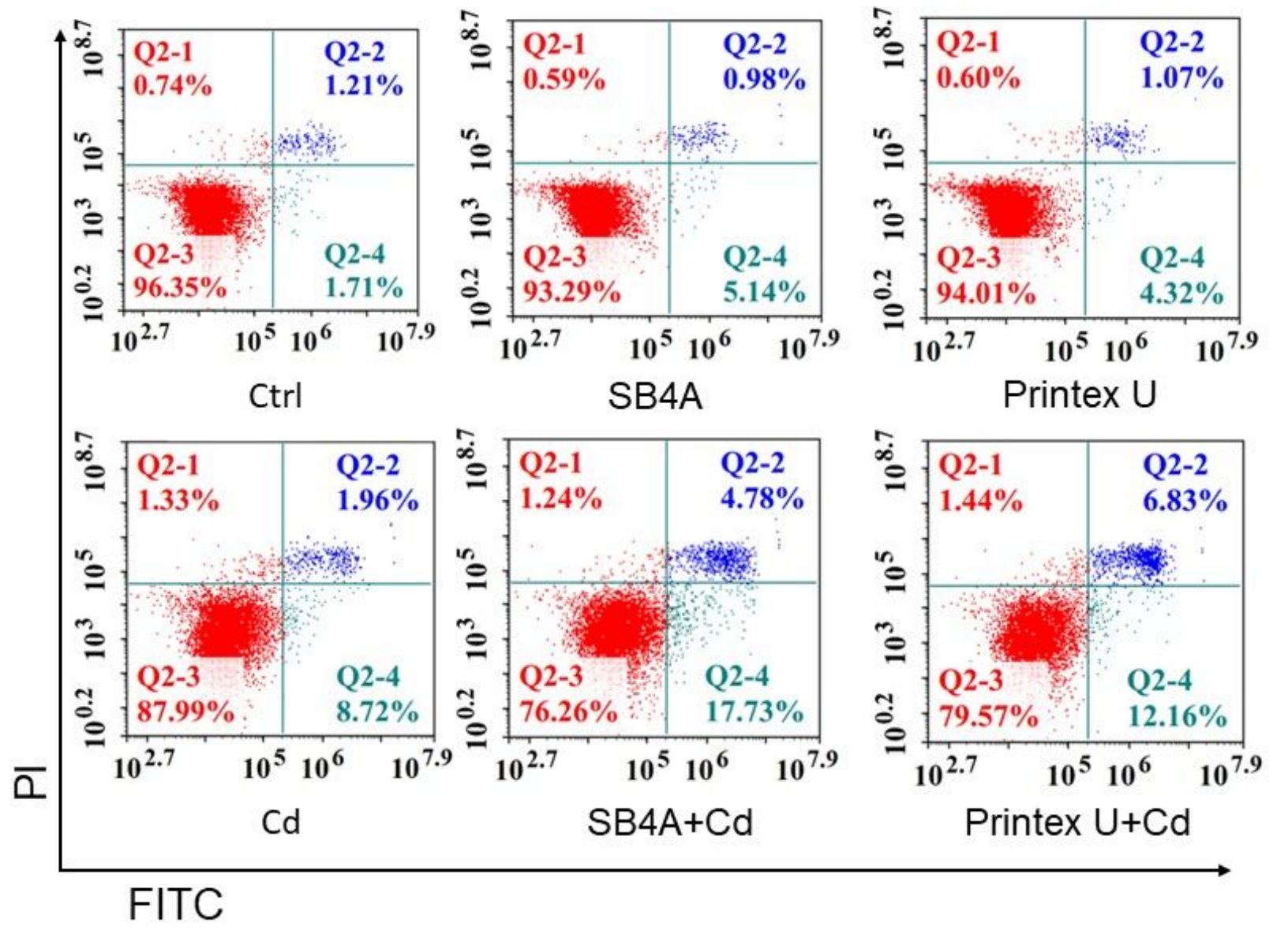

Figure 4

Synergistic apoptosis of CBs and Cd on BEAS-2B cells. Flow cytometry assay of apoptosis in BEAS-2B cells after treatment of $\mathrm{CBs}, \mathrm{Cd}$ and combination of both. 
Fig. 5
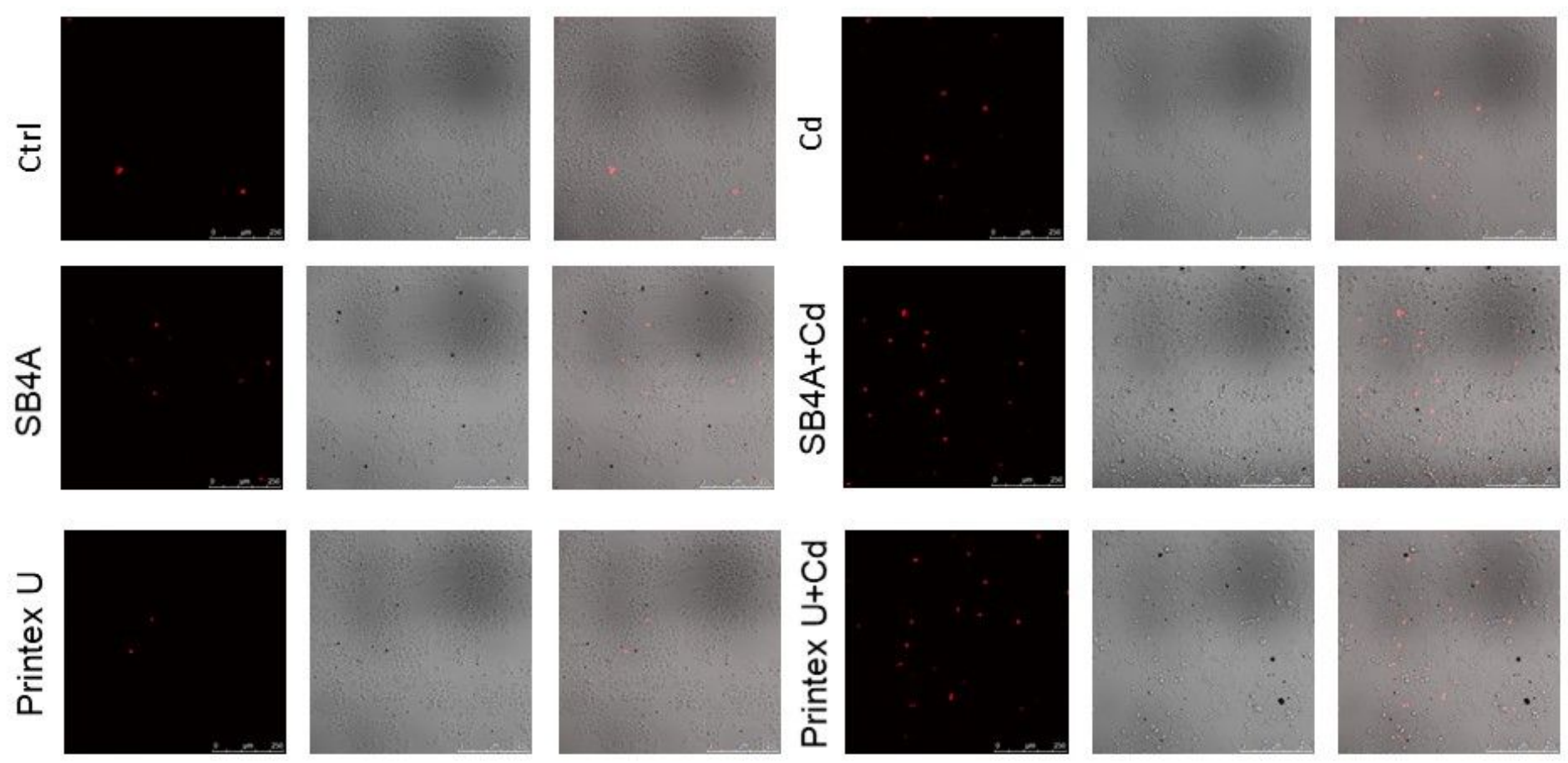

Figure 5

Synergistic apoptosis of CBs and Cd on BEAS-2B cells. Phasecontrast images with PI staining of BEAS$2 \mathrm{~B}$ cells after treatment of $\mathrm{CBs}, \mathrm{Cd}$ and combination of both. 


\section{Fig. 6}

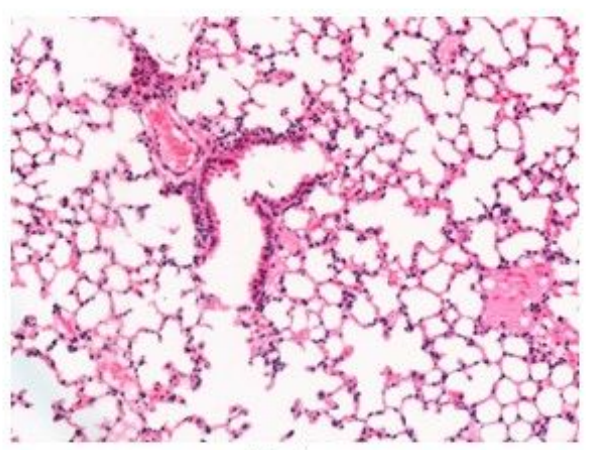

Ctrl

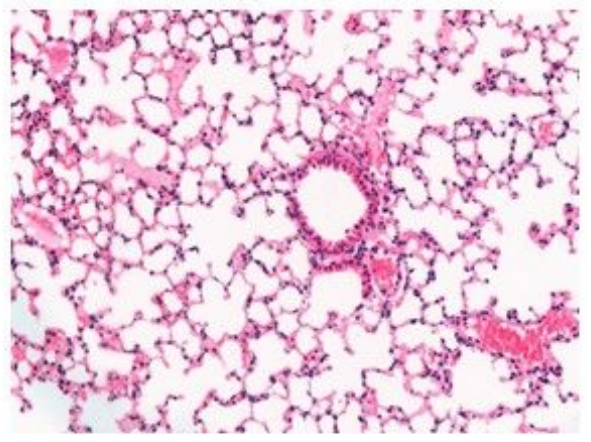

$\mathrm{Cd}$

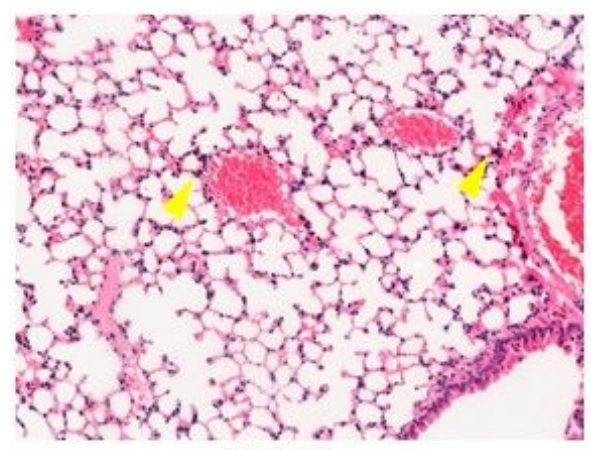

SB4A

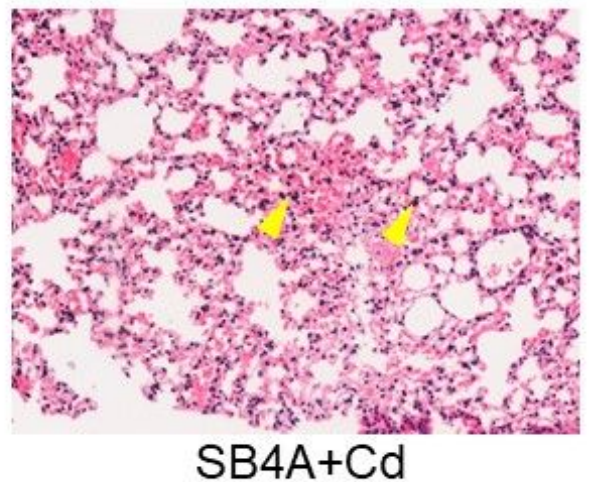

SB $4 A+C d$

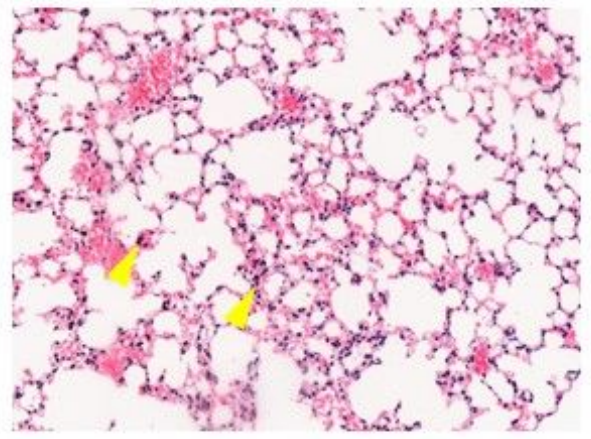

\section{Printex U}

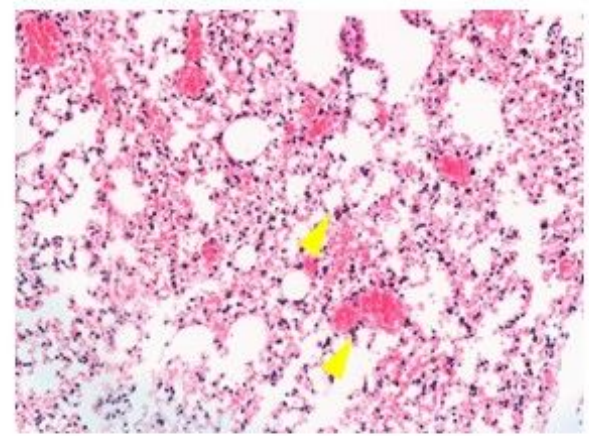

Printex $\mathrm{U}+\mathrm{Cd}$

\section{Figure 6}

Histological examination of the $\mathrm{Cd}$ with or without CBs pretreatment mice. Mice were exposed to various particles followed by histological examination of the lungs. 
Fig. 7

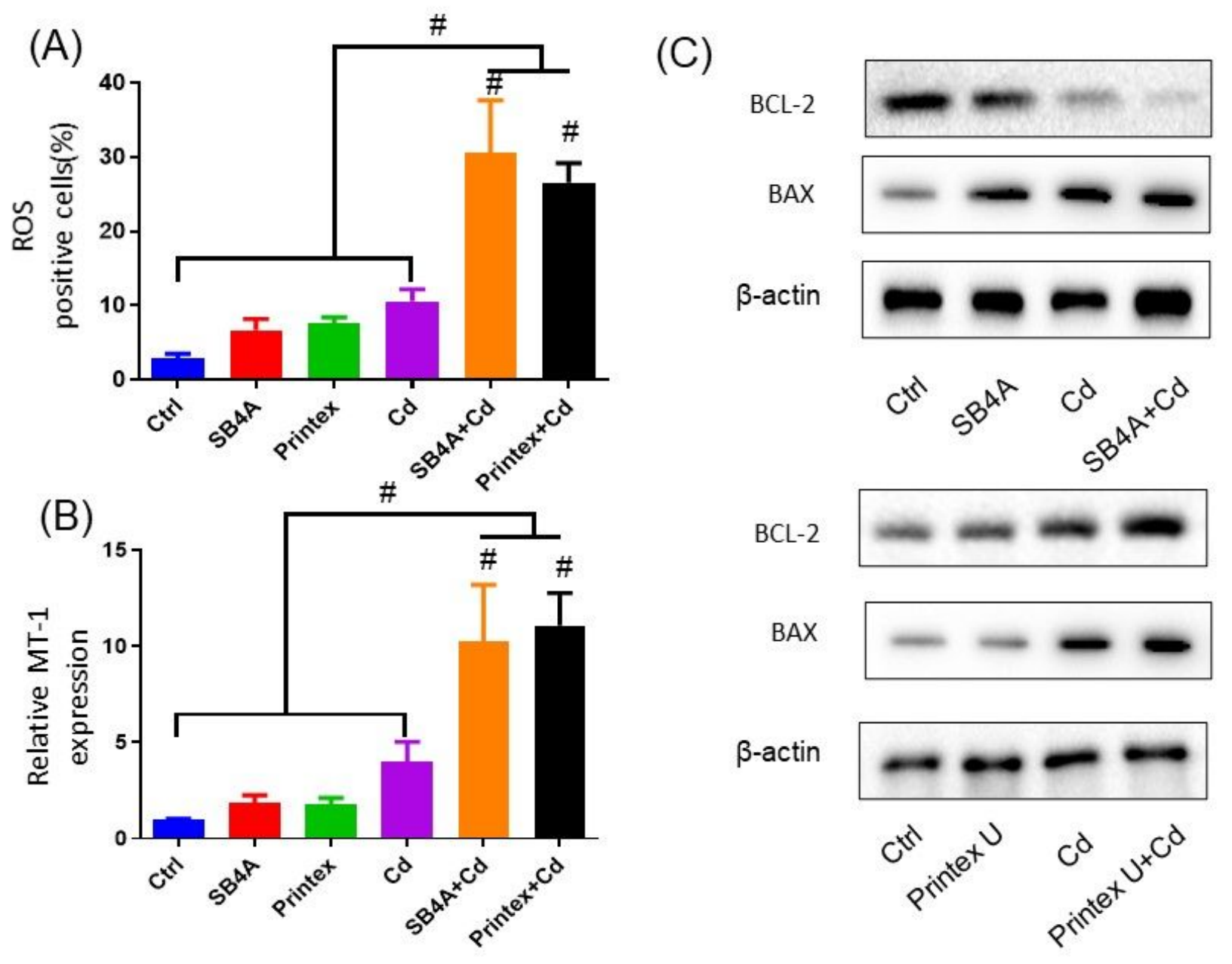

Figure 7

High intracellular concentration of Cd increased apoptosis with CB pre-treatment. (7A) ROS was increased with combination of $\mathrm{CBs}$ and $\mathrm{Cd} \mathrm{X}(7 \mathrm{~B})$ Gene expression of MT-1 in BEAS-2B cells that were pretreated with after treatment of $C B s, C d$ and combination of both $(n=5)$. ) (7C) Protein levels of BAX and $B C L-2$ in BEAS-2B cell lines after treatment of $C d$ with or without $C B s$ pretreat.

\section{Supplementary Files}

This is a list of supplementary files associated with this preprint. Click to download.

- Supplementarylnformation.docx 